2006-02-01

\title{
Up-regulation of the Notch ligand Delta-like 4 inhibits VEGF-induced endothelial cell function.
}

\section{Williams, CK}

http://hdl.handle.net/10026.1/10340

10.1182/blood-2005-03-1000

Blood

All content in PEARL is protected by copyright law. Author manuscripts are made available in accordance with publisher policies. Please cite only the published version using the details provided on the item record or document. In the absence of an open licence (e.g. Creative Commons), permissions for further reuse of content should be sought from the publisher or author. 


\title{
Up-regulation of the Notch ligand Delta-like 4 inhibits VEGF-induced endothelial cell function
}

\author{
Cassin Kimmel Williams, Ji-Liang Li, Matilde Murga, Adrian L. Harris, and Giovanna Tosato
}

Delta-like 4 (DII4), a membrane-bound ligand for Notch1 and Notch4, is selectively expressed in the developing endothelium and in some tumor endothelium, and it is induced by vascular endothelial growth factor (VEGF)-A and hypoxia. Gene targeting studies have shown that DII4 is required for normal embryonic vascular remodeling, but the mechanisms underlying DIl4 regulatory functions are currently not defined. In this study, we generated primary human endothelial cells that overexpress DII4 protein to study DII4 function and mechanism of action. Human umbilical vein endothelial cells retrovirally transduced with DII4 displayed reduced proliferative and migratory responses selectively to VEGF-A. Expression of VEGF receptor-2, the principal signaling receptor for VEGF-A in endothelial cells, and coreceptor neuropilin- 1 was significantly decreased in DII4-transduced endothelial cells. Consistent with DII4 signaling through Notch, expression of HEY2, one of the transcription factors that mediates Notch function, was significantly induced in DII4-overexpressing endothelial cells. The $\gamma$-secretase inhibitor

\begin{abstract}
L-685458 significantly reconstituted endothelial cell proliferation inhibited by immobilized extracellular DII4 and reconstituted VEGFR2 expression in DII4overerexpressing endothelial cells. These results identify the Notch ligand DII4 as a selective inhibitor of VEGF-A biologic activities down-regulating 2 VEGF receptors expressed on endothelial cells and raise the possibility that DII4 may be exploited therapeutically to modulate angiogenesis. (Blood. 2006;107:931-939)
\end{abstract}

(C) 2006 by The American Society of Hematology

\section{Introduction}

Notch signaling plays a crucial role in cell fate determinations of a variety of cell types during development and postnatally. ${ }^{1-5}$ Four Notch receptors have been identified in mammals, Notch1, ${ }^{6}$ Notch $2,{ }^{7}$ Notch $3,{ }^{8}$ and Notch $4,{ }^{9}$ and 5 ligands, Jagged $1{ }^{10}$ and Jagged $2^{11}$ belonging to the Serrate family, and Delta1, ${ }^{12}$ Delta3, ${ }^{13}$ and Delta-like 4 (Dll4) ${ }^{14-16}$ belonging to the Delta family. Ligand binding to Notch receptors triggers the proteolytic release of Notch intracellular domain which translocates into the nucleus to form a nuclear complex with the transcription factor RBP-J (also named $\mathrm{CSL}$ and $\mathrm{CBF} 1 / \mathrm{Su}(\mathrm{H}) / \mathrm{Lag}-1)$ and activates transcription of downstream target genes. ${ }^{17}$ In mammals, primary target genes of the Notch-intracellular domain/RBP-J complex include the HES (Hairy/ Enhancer of Split) ${ }^{18,19}$ and $H E Y$ (HES-related with YRPW motif, also named HERP, HES-related repressor protein) ${ }^{20-23}$ family of genes, which act as transcription factors.

A number of observations indicate that the Notch signaling pathway plays a critical role in vascular development and homeostasis. ${ }^{24-26}$ In particular, the Notchl and Notch4 genes are expressed in endothelial cells within the embryonic vasculature, $,{ }^{9}, 27-29$ and mice with targeted deletions of Notch1 alone or Notch1 plus Notch4 display severe defects in embryonic vascular remodeling with the mutant embryos dying at approximately gestational day E9.5 (embryonic day 9.5). ${ }^{30}$ Expression of activated Notch4 in the developing mouse vasculature also caused abnormal vessel struc- ture and patterning, resulting in embryonic death at approximately day E10.5. ${ }^{31}$ In addition, expression of active Notch4 in human dermal microvascular endothelial cells inhibited endothelial cell sprouting on collagen. ${ }^{32}$

Dl14 is the most recently identified Notch ligand ${ }^{14-16,33}$ and was found to interact with Notch1 and Notch4. ${ }^{14,34}$ In situ hybridization and immunocytochemistry studies showed that the predominant site of D114 expression is the vasculature, particularly the arteries, arterioles, and capillaries during development, ${ }^{14,16,35}$ and small arteries, microvessels, and tumor vessels in adult mice. ${ }^{35}$ This selectivity is unique among Notch ligands. ${ }^{30}$ Recently, mice with targeted deletions of the Dll4 gene were generated, revealing characteristic vascular remodeling defects similar to those previously observed in the Notch1 mutant and the Notch 1 and Notch4 double mutant mice. ${ }^{30,35-37}$ Strikingly, mice with heterozygous deletions of the Dll4 gene also failed to remodel the primary vascular plexus in the yolk sack and died at the embryo stage, providing evidence for the critical importance of Dl14 expression levels in vascular development. ${ }^{30,35-37}$ The $V E G F$ gene is the only other known example of inactivation of a single allele resulting in marked vascular defects and embryonic lethality in mice. ${ }^{38,39}$ In vitro, hypoxia can induce the expression of both vascular endothelial growth factor (VEGF) and D114 in endothelial cells. ${ }^{16,35,40,41}$
From the Experimental Transplantation and Immunology Branch, Center for Cancer Research, National Cancer Institute, National Institutes of Health, Bethesda, MD; and the Molecular Oncology Laboratories, Cancer Research United Kingdom, Weatherall Institute of Molecular Medicine, John Radcliffe Hospital, University of Oxford, Oxford, United Kingdom.

Submitted March 11, 2005; accepted August 2, 2005. Prepublished online as Blood First Edition Paper, October 11, 2005; DOI 10.1182/blood-2005-03-1000.

Supported by the Intramural Research Program of the National Institutes of Health (NIH), National Cancer Institute, Center for Cancer Research, and in part by "the 6th Framework Programme of the European Union [Angiotargeting]."

\section{A.L.H. and G.T. are senior coauthors.}

Reprints: Adrian L. Harris, Molecular Oncology Laboratories, Cancer Research UK, Weatherall Institute of Molecular Medicine, John Radcliffe Hospital, University of Oxford, Oxford, OX3 9DS, United Kingdom; e-mail: aharris.lab@cancer.org.uk.

The publication costs of this article were defrayed in part by page charge payment. Therefore, and solely to indicate this fact, this article is hereby marked "advertisement" in accordance with 18 U.S.C. section 1734.

(C) 2006 by The American Society of Hematology 
Taking advantage of retroviral transduction, we have expressed Dll4 in primary human endothelial cells to delineate Dll4 function in these cells. We show that Dll4 inhibits expression of VEGF receptor-2 (VEGFR2) and neuropilin-1 (NRP1) coreceptor and by this mechanism likely modulates VEGF-A-induced endothelial cell function.

\section{Materials and methods}

\section{Constructs}

The cDNA of human full-length D114 (GenBank no. AF253468) was cloned from placental cDNA using as primers hDL4B sense, 5'-GGATCCCATATGGCGGCAGCGTCCCGTAGCGCCTC-3', and hDL4E antisense, 5'GAATTCTTATACCTCCGTGGCAATGACACATTCATTC-3', followed by TA cloning into pGEM-T easy vector (Promega, Southampton, United Kingdom). Cloning accuracy was verified by DNA sequencing. Full-length Dll4 was cut from the pGEM-T easy vector using BamHI and EcoRI restriction enzymes and ligated into the retroviral plasmid LZRSpBMNlinker-IRES-EGFP. Ligation sites were sequenced, and accuracy of insertion was verified.

\section{Cells, cell culture, and reagents}

Human umbilical vein endothelial cells (HUVECs) ${ }^{42}$ were used at passages 3 to 7. The Phoenix amphotropic viral packaging cell line (Orbigen, San Diego, CA) was grown in DMEM medium (Gibco-Invitrogen, Grand Island, NY) supplemented with $10 \%$ heat-inactivated fetal bovine serum (FBS; Biofluids Rockville, MD) and $1.6 \mathrm{mM}$ L-glutamine (Sigma Chemical, St Louis, MO). Recombinant human Dll4 was from R\&D Systems (Minneapolis, MN). The $\gamma$-secretase inhibitor L-685458 (Sigma Chemical or Peptide Institute, Osaka, Japan), dissolved in dimethyl sulfoxide (DMSO; Sigma Chemical), was used at final concentrations of 0.1 to $7.5 \mu \mathrm{M}$.

\section{Virus packaging and infection}

Phoenix cells grown on 10-cm dishes to 50\% confluency were transfected with retroviral constructs using FuGENE6 (Roche Molecular Biochemicals, Indianapolis, IN) or Lipofectamine2000 (Invitrogen, Carlsbad, CA) for 24 hours. Fresh HUVEC culture medium with $2 \mu \mathrm{g} / \mathrm{mL}$ Puromycin (Sigma Chemical) was added. After reaching confluency (24-48 hours), cells were washed and cultured in Opti-MEM I (Gibco, Invitrogen) for 36 to 48 hours. The virus-containing culture supernatant was filtered $(0.4 \mu \mathrm{m})$ and added with Polybrene $(4 \mathrm{ng} / \mathrm{mL}$; Sigma Chemical) to $50 \%$ confluent HUVECs at passage 2. After 3 hours at $37^{\circ} \mathrm{C}$, cells were incubated in HUVEC culture medium for an additional 24 hours, at which time cells were washed. Subsequently, the cells were maintained under standard conditions.

\section{RNA preparation and quantitative RT-PCR}

Total RNA was extracted (Absolutely RNA Microprep Kit; Stratagene, La Jolla, CA). Quantitative reverse transcriptase-polymerase chain reaction (RT-PCR) was performed (One Step RT-PCR kit; Qiagen, Valencia, CA) with SYBR Green PCR master mix (Applied Biosystem, Foster City, CA), as described. ${ }^{43}$ The reaction was carried out in an Abi Prism 7900HT sequence detection system (Applied Biosystems). Primers used included GAPDH sense (5'-GCCACCCAGAAGACTGTGGATGGC) and antisense (5'-CATGATGGCCATGAGGTCCACCAC), Dll4 sense (5'-GACCACTTCGGCCACTATGT) and antisense ( $5^{\prime}$-CCTGTCCACTTTCTTCTCGC), HEY1 sense (5'-AACTGTTGGTGGCCTGAATC) and antisense (5'AATTCTTTGTGTTGCTGGGG), HEY2 sense (5' -TTCAAGGCAGCTCGGTAACT) and antisense (5'-GGGCATTTTACTTCCCCAAT), ephrinB2 sense (5'-GAAAATACCCCTCTCCTCAACT) and antisense (5'-CTTCGGAACCGAGGATGTTGTTC), Neuropilin-1 sense (5'CAAGGCGAAGTCTTTTGAGG) and antisense (5'-CACCTGTGAGCTGGAAGTCA), VEGFR1 sense (5'-GCACCTTGGTTGTGGCTGAC) and antisense (5'-CGTGCTGCTGCTTCCTGGTCC), VEGFR2 sense (5'-
GGAAATCATTATTCTAGTAGGCACGACG) and antisense (5'-CCTGTGGATACACTTTCGCGATG), FGFR1 sense (5'-GGAGGATCGAGCTCACTGTGG) and antisense (5'-CGGAGAAGTAGGTGGTGTCAC), VEGF-A sense (5'-CCTTGCTGCTCTACCTCCAC) and antisense (5'ATGTTGGACTCCTCAGTGGG), Notch1 sense (5'-GCAACAGCTCCT TCCACTTC) and antisense (5'-GCCTCAGACACTTTGAAGCC), Notch2 sense (5'-CCCAATGGGCAAGAAGTCTA) and antisense (5'CACAATGTGGTGGTGGGATA), Notch3 sense (5'-TCTTGCTGCTGGTCATTCTC- $\left.3^{\prime}\right)$ and antisense (5'-TGCCTCATCCTCTTCAGTTG- $\left.3^{\prime}\right)$, and Notch4 sense (5'-CACTGAGCCAAGGCATAGAC) and antisense (5'-ATCTCCACCTCACACCACTG). RT-PCR reactions were performed at $50^{\circ} \mathrm{C}$ for 30 minutes, $94^{\circ} \mathrm{C}$ for 15 minutes, 35 cycles of $94^{\circ} \mathrm{C}$ for 1 minute, $60^{\circ} \mathrm{C}\left(58^{\circ} \mathrm{C}\right.$ for Notch 3 and $55^{\circ} \mathrm{C}$ for Notch1, Notch2, and Notch4) for 1 minute, and $72^{\circ} \mathrm{C}$ for 1 minute, and $72^{\circ} \mathrm{C}$ for 10 minutes, followed by a dissociation step of 15 minutes at $95^{\circ} \mathrm{C}, 15$ minutes at $60^{\circ} \mathrm{C}$, and 15 minutes at $95^{\circ} \mathrm{C}$.

\section{Cell-cycle analysis and flow cytometry}

Cell-cycle analysis was carried out in HUVECs synchronized by 24 hours in "starvation medium" consisting of M199 (Gibco-Invitrogen) with 2.5\% FBS (Biofluids), $25 \mu \mathrm{g} / \mathrm{mL}$ porcine heparin (Sigma Chemical) or in exponentially growing HUVECs. Cells were incubated in starvation medium supplemented with $50 \mathrm{ng} / \mathrm{mL}$ VEGF-A (R\&D Systems). Where noted, cells were pulsed with $10 \mu \mathrm{M} \mathrm{5}$ '-Bromo-2'-deoxyuridine (BrdU; Sigma Chemical) by incubation for 1 hour prior to harvest. At intervals (0-72 hours), cells were detached with $0.05 \%$ Trypsin/ethylenediaminetetraacetic acid (EDTA) (Gibco, Invitrogen), washed, suspended in 0.5 to 1 $\mathrm{mL}$ cold $70 \%$ ethanol in PBS. After washing, incubation with $2 \mathrm{M}$ $\mathrm{HCl} /$ Triton $\mathrm{X}-100$ for 30 minutes at room temperature, neutralization and suspension in PBS containing 0.5\% Tween-20 and 1\% BSA, cells were incubated with FITC-labeled mouse monoclonal anti-BrdU antibody (Becton Dickinson Immunocytometry Systems, San Jose, CA). For propidium iodide (PI) incorporation, cells were suspended in PBS with $50 \mu \mathrm{g} / \mathrm{mL}$ PI (Sigma Chemical) and $100 \mathrm{U} / \mathrm{mL}$ Ribonuclease A (RNase; Sigma Chemical), incubated at $37^{\circ} \mathrm{C}$ for 30 minutes, and rinsed with PBS. At least 10000 events were acquired, and results were analyzed with CellQuest (Becton Dickinson, Franklin Lakes, NJ) and MODFIT $L T$ software (Topsham, ME), as described. ${ }^{44}$ For flow cytometric analysis of enhanced green fluorescent protein (EGFP) expression, HUVECs were suspended in $0.5 \mathrm{~mL}$ PBS and examined. ${ }^{43}$ Flow cytometric analysis of surface antigens was performed as described. ${ }^{42}$ For VEGFR2 staining, we used mouse monoclonal antiVEGFR2 (ab9530; Abcam, Cambridge, MA) and Alexa594-labeled goat antimouse antibody (Molecular Probes, Eugene, OR). Control staining was with mouse IgG1 and Alexa594-labeled goat antimouse antibody. For neuropilin-1 staining, we used PE-labeled mouse monoclonal antiBDCA-4 (human neuropilin-1) antibody (AD5-17F6 clone; Miltenyi Biotec GmbK, Bergisch Gladbach, Germany) and for CD31 staining a PE-labeled mouse monoclonal anti-human CD31 antibody (Pharmingen, BD Biosciences, San Diego, CA). Data were collected using a fluorescenceactivated cell sorting (FACS) Calibur flow cytometer (Becton Dickinson) and were analyzed using CELLQuest software (Becton Dickinson).

\section{Immunocytochemistry}

A rabbit immune serum against human D114 (named R3) was produced by immunization with recombinant intracellular domain of D1l4 produced in Escherichia coli. Human Dll4 intracellular domain was cloned into the expression vector pET-28C-D4ICD, using primers: sense 5'-GGATCCCATATGCGTCAG-CTGCGTCTTCGTCGTCCGG-3' and hDl4E antisense (see "Constructs"). PCR product was cloned into pGEM-T easy vector to produce the pGEM-T-D4ICD plasmid. The plasmid was then digested with $N d e \mathrm{I}$ and $E c o$ RI restriction enzymes, and the fragment was inserted into pET-28C to produce the pET-28C-D4ICD expression vector. The vector was transformed into BL21 Codon ${ }^{+}$competent cells for expression of recombinant protein, $(\mathrm{MX} 3 \mathrm{H} 6 \times 10$.D4ICD). D114 intracellular domain was purified from inclusion bodies and used for rabbit immunization. Cytospin preparations of HUVECs (10-20 000 cells/slide, $38.2 \mathrm{~g}$ for 6 minutes) were fixed with acetone for 10 minutes at room 
temperature, washed with PBS over 20 minutes, blocked with $10 \%$ fetal bovine serum in PBS, incubated with R3 rabbit antibody (1:300 dilution in PBS containing $3 \% \mathrm{FBS}, 1$ hour at $37^{\circ} \mathrm{C}$ ), washed in PBS over 20 minutes, and then incubated with a goat antirabbit antibody labeled with horseradishperoxidase (DAKO, Carpinteria, CA) for 30 minutes at $37^{\circ} \mathrm{C}$. After washing, slides were incubated 30 minutes at room temperature in 3-amino-9-ethylcarbazol (AEC) substrate $(21 \mathrm{~mL} 0.1 \mathrm{M} \mathrm{Na}$ acetate $79 \mathrm{~mL}$ plus $0.1 \mathrm{M}$ acetic acid plus $6 \mathrm{~mL}$ AEC, $100 \mu \mathrm{L} 30 \% \mathrm{H}_{2} \mathrm{O}_{2}$ ) and counterstained with Meyer hematoxylin for 5 to 10 minutes.

\section{Western blotting and VEGF ELISA}

Immunoblotting was performed as described ${ }^{45}$ For Dl14 recognition, we used rabbit R3 anti-human Dll4 antibody (dilution 1:250) with an affinity-purified, peroxidase-linked, donkey IgG antirabbit antibody (Amersham Biosciences, Piscataway, NJ); a mouse monoclonal anti-human/ mouse D114 (MAB1389, 1:500 dilution; R\&D Systems) with a peroxidaselinked donkey $\operatorname{IgG}$ antimouse antibody; or an affinity-purified goat anti-Dl14 peptide antibody (C-20, 1:500 dilution; Santa Cruz Biotechnology, Santa Cruz, CA) with a peroxidase-linked donkey anti-goat IgG antibody (Santa Cruz Biotechnology). For identification of $\beta$-actin, we used a goat IgG anti-actin antibody (C11, 1:1000 dilution; Santa Cruz Biotechnology) with a donkey anti-goat IgG HRP-conjugated (Santa Cruz Biotechnology). Antibody detection was by chemiluminescence using enhanced chemiluminescence (ECL; Amersham Pharmacia Biotech, Piscataway, NJ). VEGF-A was measured by enzyme-linked immunosorbent assay (ELISA; R\&D Systems; lower limit of detection approximately $3 \mathrm{pg} / \mathrm{mL}$ ).

\section{Cell proliferation assay}

HUVEC proliferation was measured as described. ${ }^{42}$ HUVECs were seeded in triplicate in 96-well plates $\left(2-4 \times 10^{3}\right.$ cells/well in $0.2 \mathrm{~mL}$ RPMI 1640 culture medium supplemented with $18 \%$ heat-inactivated FBS [Biosource, Camarillo, CA]) and $18 \mathrm{U} / \mathrm{mL}$ porcine heparin, with or without human VEGF-A $_{165}$ (3-24 ng/mL; R\&D Systems) or human bFGF (3-28 ng/mL; R\&D Systems) and incubated for 3 days. HUVECs were also cultured onto microtiter 96-well plates that were preincubated for 18 hours at $4^{\circ} \mathrm{C}$ with 50 $\mu \mathrm{L}$ recombinant human D114 ( $1 \mu \mathrm{g} / \mathrm{mL}$ in PBS or gelatin; R\&D Systems). When L-685458 was used, medium was replenished every 24 hours with inhibitor or DMSO control. Proliferation was measured by ${ }^{3} \mathrm{H}$-thymidine deoxyribose uptake $(0.5 \mu \mathrm{Ci}[0.0185 \mathrm{MBq}] /$ well, $25 \mathrm{Ci} / \mathrm{mmol}[925$ $\mathrm{GBq} / \mathrm{mmol}$; New England Nuclear, Boston, MA) during the last 18 to 22 hours of culture. Results are expressed as mean $( \pm \mathrm{SEM}) \mathrm{cpm} /$ culture.

\section{Matrigel cord formation assay}

The in vitro matrigel assay was performed essentially as described. ${ }^{45}$ HUVECs were plated (40 000-75 000 cells) onto 24-well tissue culture plates coated with 200 to $300 \mu \mathrm{L}$ solidified matrigel (an extract of the Englebreth-Holm-Swarm tumor, Collaborative; BD Pharmingen, San Diego, CA). After 16 to 18 hours of incubation, cells were photographed (Retiga 1300 digital camera; Qimaging, Burnaby, BC, Canada) under phase-contrast microscopy (Olympus $1 \times 51$ with a $10 \times 0.25 \mathrm{NA} \mathrm{PhL}$ lens; Olympus Optical, Melville, NY), and images were obtained with IPLab for Windows software (Scanalytics, Fairfax, VA) imported into Adobe Photoshop (Adobe Systems, San Jose, CA). Network formation was measured by counting the number of cord angles/field (each field is defined as the area visualized by a $4 \times$ magnification lens). Each experimental condition was tested in 8 separate experiments.

\section{Migration assay}

Endothelial migration assays were performed using $0.2 \%$ gelatin-coated polycarbonate filters (pore size $8 \mu \mathrm{m}$ ) of transwells; Costar, Cambridge, MA). HUVECs transduced with empty vector or D1l4 $\left(5 \times 10^{5} /\right.$ well $)$ were placed in the upper chamber in migration medium (RPMI 1640 containing $0.5 \%$ BSA and $10 \mathrm{mM}$ HEPES). The lower chamber contained migration medium with or without $100 \mathrm{ng} / \mathrm{mL}$ VEGF-A or $100 \mathrm{ng} / \mathrm{mL}$ bFGF. After 16 to 20 hours of incubation at $37^{\circ} \mathrm{C}$, viable cells in the lower chamber were counted.

\section{Statistical analysis}

Group differences were evaluated by Student $t$ test; $P$ values less than .05 were considered significant.

\section{Results}

\section{Up-regulation of DII4 in primary human endothelial cells}

We selected retrovirus-mediated transduction to overexpress Dll4 in primary human endothelial cells derived from the umbilical vein (HUVECs) to achieve moderate levels of Dll4 expression. In culture, HUVECs constitutively express low-level Dll4 mRNA detected by RT-PCR. ${ }^{42}$ We found that approximately $90 \%$ of HUVECs expressed enhanced green fluorescent protein (EGFP) on day 3 after infection with the control retrovirus (Figure 1A). A similar proportion of HUVECs (92\%) expressed EGFP on day 3 after infection with Dll4 retrovirus (Figure 1A). When infection efficiency fell below $60 \%$, cells were FACS sorted for $100 \%$ EGFP expression. The proportion of EGFP-positive cells decreased on the average by approximately $15 \%$ over 7 to 10 days after infection. All
A

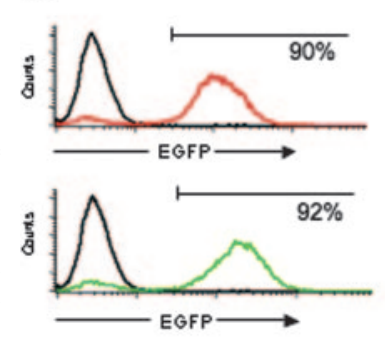

Figure 1. DII4 expression in retrovirally transduced primary human endothelial cells. (A) Flow cytometric measurement of EGFP expression in HUVECs infected 3 days earlier with control retrovirus or DII4 retrovirus. Representative images from 8 independent infections. (B) Levels of DIl4 expression in HUVECs 3 to 15 days after transduction with control vector or DII4 retrovirus were evaluated by quantitative RT-PCR relative to GAPDH expression. The results reflect the mean ( \pm SEM) from 14 separate determinations from 8 infections. ${ }^{\star} P=.012$. (C) DII4 and actin expression in HUVECs transduced with control vector or DII4 retrovirus evaluated by immunoblotting with R3 rabbit anti-DII4 antibody and reblotting with goat anti- $\beta$-actin antibody. (D-F) Immunocytochemical analysis of DII4 expression in HUVECs transduced with DII4 (F) or vector only (D) using rabbit anti-DII4 antibodies; control staining of Dll4-transduced HUVECs with preimmune rabbit serum $(E)$.

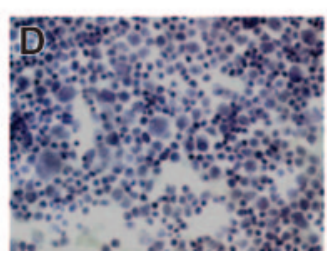

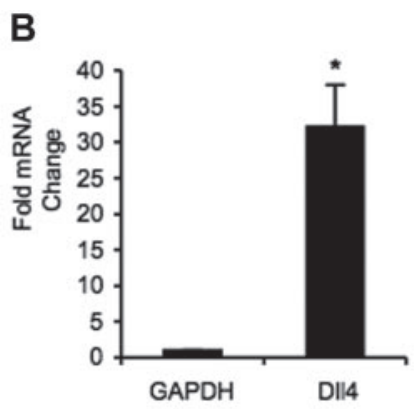
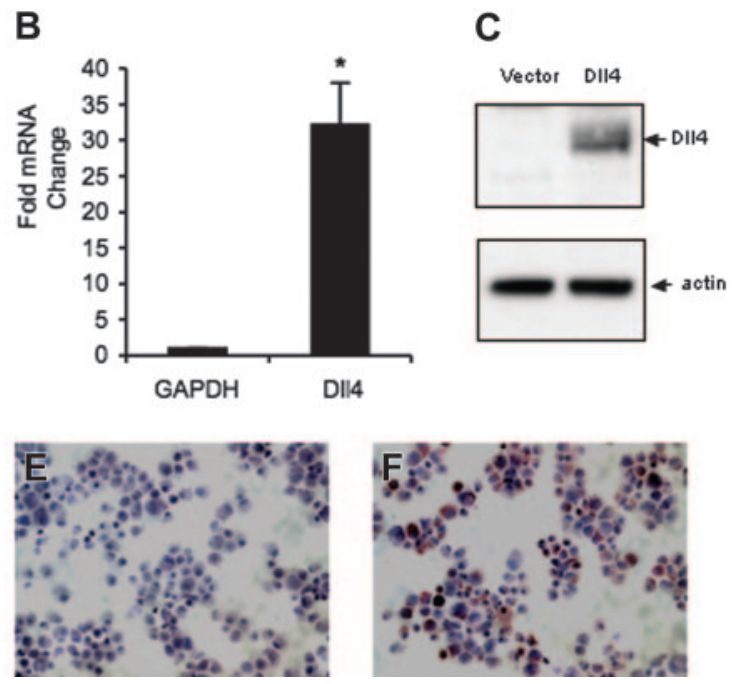
results were obtained from 8 separate populations of cells in which greater than $50 \%$ of cells were positive for EGFP.

By quantitative real-time PCR analysis, we found that Dll4 transcript levels were significantly higher in Dll4 cells than in control cells. In 14 determinations from 8 separate infections, levels of Dll4 expression normalized to GAPDH were $32- \pm 5.9$ fold (mean \pm SEM) higher $(P<.001)$ in Dll4 cells than in the control cells (Figure 1B).

By immunoblotting, we found that antibody R3 we raised against the intracellular domain of Dll4 identified a band migrating at approximately $70 \mathrm{kDa}$ in cell extracts from Dll4-transduced cells but not in cell extracts from the control cells (Figure 1C). The predicted molecular weight of full-length Dll4 is calculated to be $75 \mathrm{kDa}$. This difference could not be attributed to uneven loading as demonstrated by membrane reblotting with antibodies directed against actin (Figure 1C). Similar results showing D114 protein expression in D114 cells were derived from membrane reblotting with a purified rat monoclonal antibody raised against recombinant Dll4 (R\&D Systems) and with an affinity-purified goat polyclonal antibody directed against a C-terminal peptide of Dll4 (Santa Cruz Biotechnology) (not shown). We conclude that Dll4-transduced HUVECs express D114 protein, whereas control HUVECs express insufficient amounts of D114 protein to be detected by Western blotting.

Up-regulation of Dll4 protein in transduced HUVECs was confirmed by immunocytochemical staining of cytospin preparations. HUVECs infected with the Dll4 retrovirus were Dll4positive (brown staining) when immunostained by the R3 antibody (Figure 1F). By contrast, HUVECs infected with the wild-type vector (Figure 1D) were essentially negative. In addition, a preimmune rabbit serum (from the same rabbit producing R3) did not immunostain HUVECs transduced with Dll4 (Figure 1E). Thus, these results demonstrate that primary human endothelial cells can be transduced to overexpress Dll4.

Effects of DII4 overexpression on endothelial cell proliferation and cell-cycle progression

We examined the effects of Dll4 overexpression on HUVECs growth in response to the proangiogenic factors vascular endothelial growth factor (VEGF)-A and basic fibroblast growth factor (bFGF). To best evaluate the effects of Dll4 overexpression rather than clonal variation, we selected for functional experiments HUVEC cultures in which similar proportions of cells were EGFP-positive after infection with control and Dll4 retrovirus, reflecting effective and comparable transduction levels. When stimulated for 3 days in the presence of VEGF-A $(25 \mathrm{ng} / \mathrm{mL})$, Dll4-transduced HUVECs consistently proliferated to a significantly lower degree $(P<.001)$ than the control cells (Figure $2 \mathrm{~A})$.

This difference was observed over a wide range of VEGF-A concentrations (Figure 2B; representative experiment). Consistent with this reduced proliferative capacity of Dll4-overexpressing HUVECs, there were significantly fewer cells in VEGF-A (25 $\mathrm{ng} / \mathrm{mL}$ )-supplemented cultures of Dll4-transduced HUVECs compared with the control HUVECs (not shown). In a representative experiment (of 4 performed), there were $115 \times 10^{3}$ Dll4transduced viable HUVECs as opposed to $216 \times 10^{3}$ control HUVECs after 3-day incubation. In contrast to their reduced proliferative response to VEGF-A, Dll4-transduced and control HUVECs proliferated similarly in response to bFGF at varying concentrations (Figure 2C; representative experiment). Thus, D114

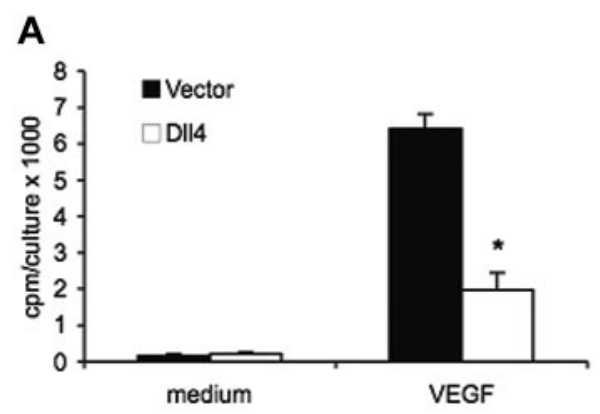

B
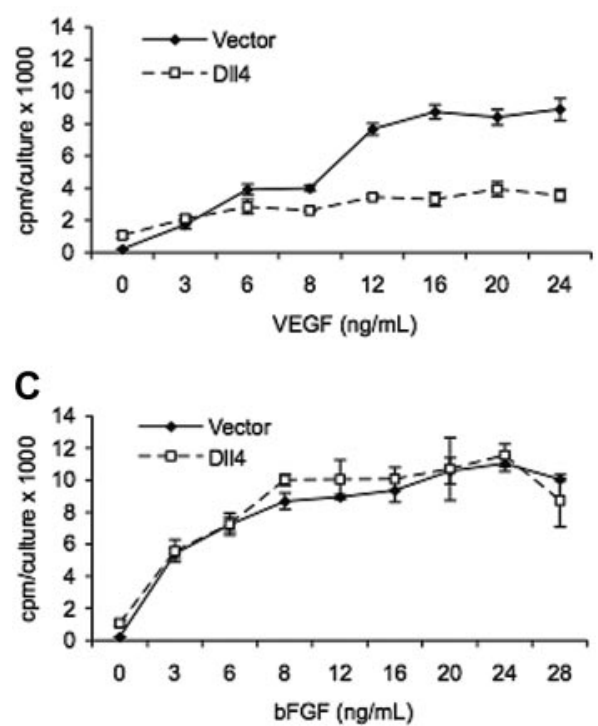

Figure 2. Effects of DII4 expression on endothelial cell proliferation. (A) HUVECs transduced 3 to 10 days earlier with either vector only or DII4 (70\%-90\% of cells expressing EGFP) were cultured for 72 hours in medium alone or medium supplemented with VEGF-A $(25 \mathrm{ng} / \mathrm{mL})$; proliferation was measured by $\left[{ }^{3} \mathrm{H}\right]$ thymidine deoxyribose uptake during the last 18 hours of culture. The results reflect the means ( \pm SEMs) from 5 separate experiments, each performed in triplicate cultures. ${ }^{\star} P<.001$. (B) Dose dependency of VEGF-A (3-24 ng/mL) induced HUVEC proliferation 3 to 10 days after transduction with vector only or DII4 retrovirus. Cell proliferation was measured as described in "Materials and methods"; the results reflect the means ( \pm SDs) of triplicate cultures (representative of 4 determinations). (C) Analysis of HUVEC proliferation in response to bFGF $(3-28 \mathrm{ng} / \mathrm{mL}) 3$ to 10 days after transduction with vector alone or DII4 retrovirus. Cell proliferation was measured as described in "Materials and methods"; the results reflect the means ( \pm SDs) of triplicate determinations (representative of 4 determinations).

overexpression in primary human endothelial cells is associated with reduced proliferation in response to VEGF-A.

To characterize this reduced proliferative capacity of Dll4overexpressing HUVECs in response to VEGF-A, we examined cell-cycle distribution during VEGF-A stimulation. First, the cells were synchronized by culture for 24 hours under starvation conditions (serum concentration in the culture medium was reduced 2.5\%; ascorbate and ECGS omitted) and then stimulated with VEGF-A (50 ng/mL) in starvation medium. Initially (0 time point), the cell distribution in the different phases of the cell cycle was similar in control and Dll4 HUVECs, reflecting a similar proliferative capacity of these cells in the presence of endothelial cell growth supplement, which contains bFGF and acidic FGF, used for culture maintenance (Figure 3A, representative experiment of 4 performed). However, at subsequent time points ( 24 and 48 hours), a clear difference in cell-cycle progression between control cells and Dll4-overexpressing HUVECs was noted. In the control cultures (vector), the percentage of cells in the $G_{0} / G_{1}$ phase 

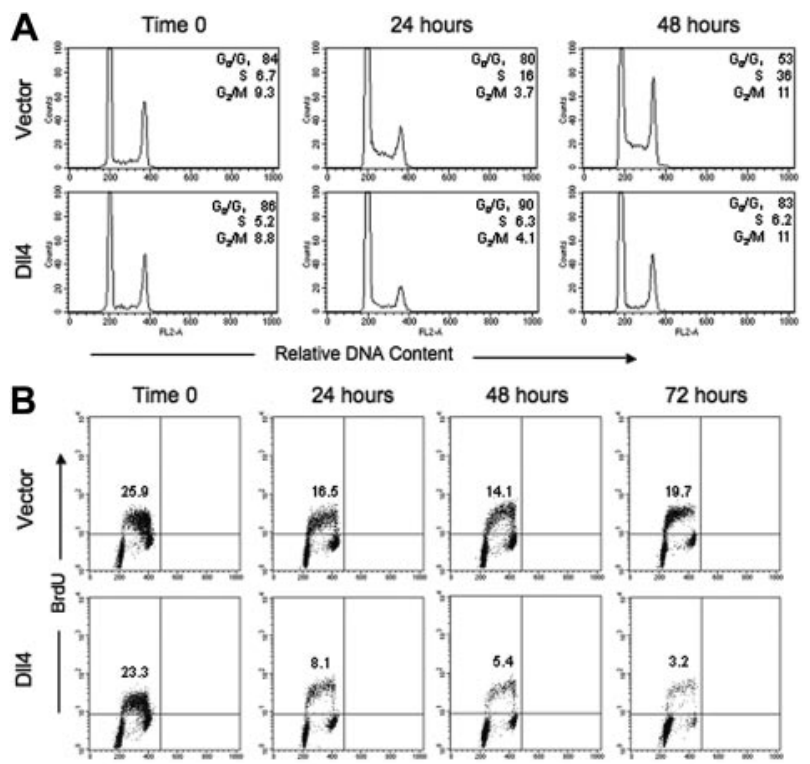

言
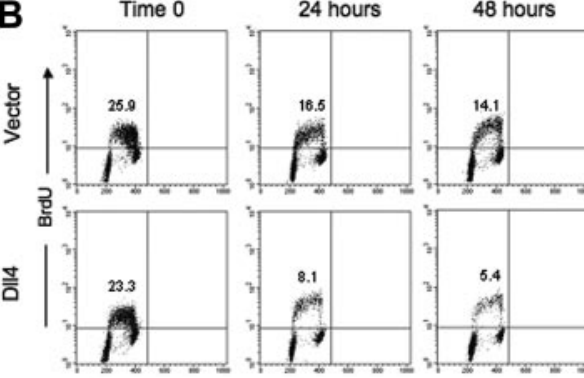

Relative DNA Content

Figure 3. Analysis of the effects of DII4 overexpression on cell-cycle distribution. (A) HUVECs transduced with DII4 or vector only (60\%-90\% of cells expressing EGFP) were synchronized by 24-hour incubation in starvation medium supplemented with $2.5 \%$ serum and then stimulated with VEGF-A $(50 \mathrm{ng} / \mathrm{mL})$ for 24 or 48 hours. Cell-cycle distribution was evaluated by flow cytometric analysis of relative DNA content, after cell fixation in cold $70 \%$ ethanol and incorporation of propidium iodide (PI). The results, analyzed by MODFIT LT software, reflect the percentage of cells found in the $G_{0} / G_{1}, S$, and $G_{2} / M$ phases of the cell cycle at time 0 (end of synchronization), 24 and 48 hours after culture with VEGF-A. Representative experiment of 4 performed. (B) Exponentially growing HUVECs transduced with vector only or DII4 (60\%-90\% of cells expressing EGFP) were cultured in serumreduced $(2.5 \%)$ medium containing VEGF-A $(50 \mathrm{ng} / \mathrm{mL})$ for 24 to 72 hours. Cells were pulsed with BrdU $(10 \mu \mathrm{M})$ over 1 hour prior to harvest. After fixation in $70 \%$ ethanol and Triton-X 100 permeabilization, the cells were stained with FITC-labeled mouse monoclonal anti-BrdU antibodies and subsequently allowed to incorporate PI. Cell-cycle distribution was evaluated by flow cytometry. The results reflect the percentage of cells in the $S$ phase of cell cycle measured at time 0 ( 1 hour after culture in serum-reduced medium), 24, 48, and 72 hours after incubation in VEGF-A-supplemented serum-reduced culture medium.

of cell cycle fell from $84 \%$ (time 0 ) to $53 \%$ after 48 -hour starvation in the presence of VEGF-A, whereas the percentage of cells in the $\mathrm{S}$ phase of the cell cycle correspondingly increased from $6.7 \%$ to $36 \%$. Under the same culture conditions and testing, the percentage of Dll4-transduced HUVECs (Dll4) in the $\mathrm{G}_{0} / \mathrm{G}_{1}$ phase of cell cycle fluctuated between $83 \%$ and $90 \%$, and the percentage of cells in $\mathrm{S}$ phase fluctuated only between $5 \%$ and $6 \%$ (Figure 3A). These experiments provided evidence that, after stimulation with VEGF-A, HUVECs overexpressing Dll4 have a reduced capacity to enter S phase compared with control cells.

Additionally, we confirmed this observation by measuring the fraction of cells in the $S$ phase of the cell cycle based on BrdU and PI incorporation. Exponentially growing, unsynchronized HUVECs were incubated for 72 hours in culture medium containing $2.5 \%$ serum and $50 \mathrm{ng} / \mathrm{mL}$ VEGF. Under these restrictive culture conditions, the proportion of BrdU-positive cells in the $\mathrm{S}$ phase of the cell cycle decreased over 72 hours in both control and Dll4-transduced HUVECs, despite the presence of VEGF-A, but the reduction was greater in Dll4-overexpressing cells as compared with control cells (Figure 3B).

\section{Effects of DII4 overexpression on endothelial cell migration and matrix-dependent cord formation}

These results provided evidence that Dl14-overexpressing endothelial cells are defective in their ability to replicate in response to
VEGF-A. We examined whether this defect was limited to VEGF-A-induced proliferation or extended to other nonmitogenic functions of VEGF-A. In migration assays, VEGF-A (100 ng/mL) and bFGF (100 ng/mL) promoted a significant response from control HUVECs (Figure 4A). However, VEGF-A induced only modest migration from Dll4-overexpressing HUVECs, which was significantly $(P=.021)$ reduced compared with the control HUVECs. This difference was not associated with a more global defect in cell migration, because Dll4-overexpressing HUVECs and control HUVECs migrated to a similar degree $(P=.74)$ in response to bFGF (Figure $4 \mathrm{~A}$ ).

In additional analyses of nonmitogenic activities of VEGF-A, we examined the ability of endothelial cells to undergo a morphogenic change into cordlike structures. When incubated on extracellular matrices, such as collagen, fibrin, or matrigel (a mixture of the extracellular matrix proteins laminin, collagen IV, heparan sulfate proteoglycans, and entactin-nidogen), primary endothelial cells can form a characteristic network of cordlike structures. ${ }^{43,45}$ With HUVECs, matrigel-induced cord formation takes place over 6 to 16
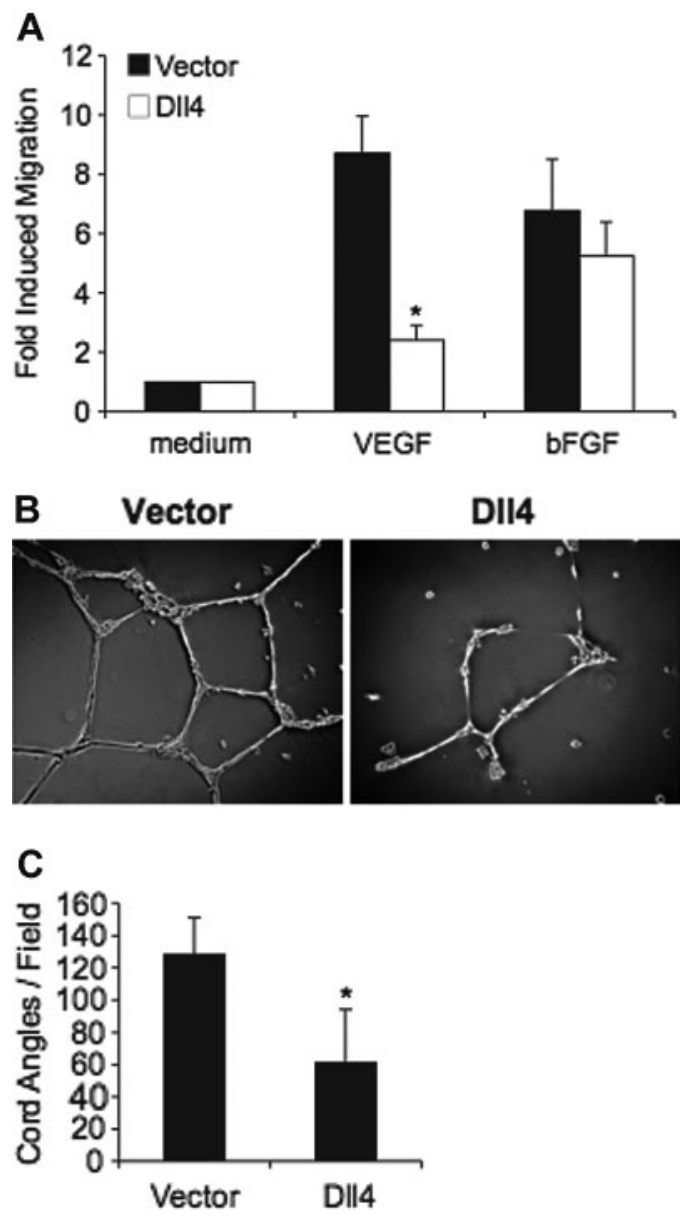

Figure 4. Effects of DII4 overexpression on endothelial cell migration and extracellular matrix-dependent cord formation. (A) VEGF-A (100 ng/mL)- and bFGF $(100 \mathrm{ng} / \mathrm{mL})$-induced transwell migration of control and DIl4-overexpressing HUVECs $\left(5 \times 10^{5}\right.$ cells/well) over 16 to 20 hours of incubation. The results reflect the mean fold increase ( \pm SEM) in cell migration compared with medium alone in 3 experiments performed in triplicate. (B) Representative images reflecting cord formation by control and DII4-overexpressing HUVECs $\left(4-7.5 \times 10^{4}\right.$ cells/well) plated in complete culture medium on matrigel-coated wells (24-well plate) and incubated 16 to 18 hours. Phase-contrast microscopy (original magnification, $\times 10)$. (C) Quantitative analysis of matrigel-induced cord formation in control and DII4-overexpressing HUVECs. Cord formation was measured as a function of the number of cord angles per visual field (phase-contrast microscopy, $4 \times$ magnification). The results represent the mean $( \pm \mathrm{SD})$ from 8 independent experiments. ${ }^{\star} P=.001$. 
hours of incubation, does not require cell division, and is critically dependent on endogenous VEGF-A and other factors. ${ }^{45-49}$ As shown in a representative experiment (Figure 4B), the control HUVECs formed the characteristic network of orderly branching cordlike structures, Dl14-overexpressing HUVECs formed many fewer such structures so that the network was often incomplete. Quantitative analysis of network formation in 8 independent experiments by measuring cord branching angles revealed that Dll4-overexpressing HUVECs were significantly $(P=.031)$ defective in their ability to form networks compared with control cells (Figure 4C).

\section{VEGFR2 and ephrinB2 modulation in endothelial cells that overexpress DII4}

We examined whether the reduced capacity to assemble into cordlike structures by Dll4-overexpressing cells might be attributable to reduced expression of endogenous VEGF, which is required for this morphogenic process. By quantitative RT-PCR analysis, we found that levels of VEGF mRNA were similar $(P=.82)$ in the control- and Dll4-transduced HUVECs (Figure 5A). In addition, culture supernatants from the control cells and Dll4-overexpressing cells contained similar levels of VEGF (52 and $61 \mathrm{pg} / \mathrm{mL}$, respectively) after 20 hours of incubation on matrigel. This provides evidence that D114 does not regulate VEGF expression in HUVECs and suggests that reduced VEGF-A expression is not the reason underlying defective matrigel-dependent network formation by Dll4-overexpressing HUVECs.
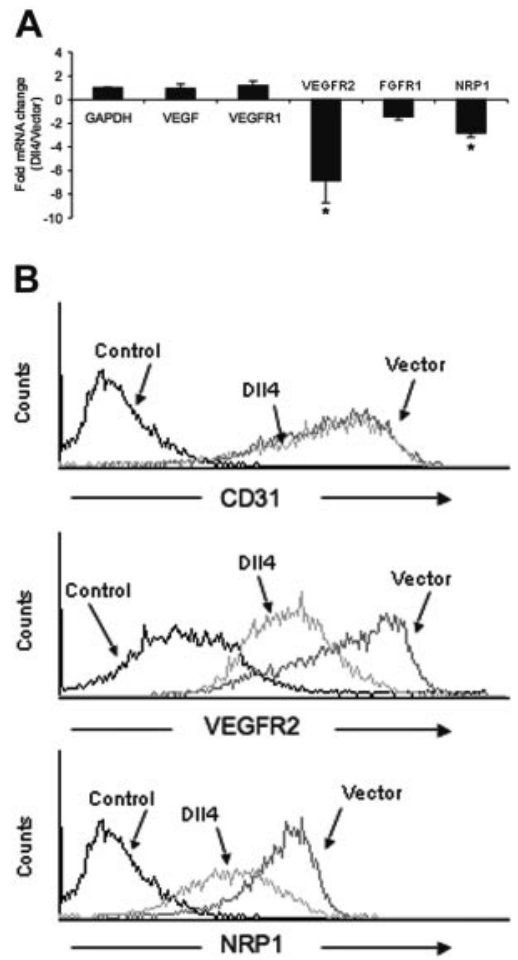

Figure 5. Regulation of VEGFR2 and NRP1 expression in Dll4-transduced endothelial cells. (A) Quantitative RT-PCR analysis of VEGF-A, VEGFR1, VEGFR2, FGFR1, and NRP1 expression in HUVECs transduced with vector only or DIl4. The results reflect relative mRNA levels (normalized to GAPDH) in DII4-transduced and control HUVECs and are expressed as the fold mRNA change in DIl4 versus control HUVECs. The results represent the mean ( \pm SEM) from 4 to 9 independent determinations. ${ }^{*} P<.05$. (B) Surface levels of CD31, VEGFR2, and NRP1 expression in vector-only (Vector) and DII4-transduced (DII4) HUVECs measured by flow cytometry. Control reflects background surface fluorescence staining with appropriate controls.
On the basis of the observation that Dll4 overexpression is associated with selectively reduced endothelial cell responses to VEGF-A, we examined VEGFR2 expression in Dll4-overexpressing HUVECs. It is known that VEGFR2 serves as the principal signaling receptor for endothelial cell proliferation, migration, survival, and angiogenesis induced by VEGF-A. ${ }^{50}$ By quantitative RT-PCR analysis, we consistently (5 determinations) found that VEGFR2 mRNA levels were significantly $(P=.035)$ reduced in Dll4-overexpressing HUVECs in comparison with control HUVECs, whereas levels of VEGFR1 and FGFR1 mRNAs were similar $(P>.1$; Figure 5A). Additionally, we consistently (7 determinations) found that RNA levels of NRP1, a coreceptor for VEGF-A that enhances VEGF-A binding to VEGFR2,51 were significantly $(P=.003)$ reduced in Dll4-transduced cells compared with control cells (Figure 5A). By flow cytometry, levels of surface VEGFR2 and NRP1 expression were markedly reduced in Dll4overexpressing HUVECs compared with control HUVECs, whereas levels of surface CD31 were similar (Figure 5B).

\section{Notch expression in HUVECs and contribution of Notch engagement to the phenotype of DII4-transduced HUVECs}

We looked for evidence of Notch expression in the HUVECs. By RT-PCR, we determined that the vector-transduced HUVECs used in the current experiment, express mRNA for the Notch receptors Notch1, Notch2, and Notch4 but only low-level Notch3 mRNA (Figure 6A). By quantitative RT-PCR analysis, we found that HEY2 mRNA levels were consistently and significantly $(P=.013)$ increased in Dll4-transduced HUVECs compared with controls, whereas HEY1 mRNA levels were similar $(P=.2$; Figure $6 \mathrm{~B})$. Also, we found that ephrinB2 mRNA levels were significantly $(P=.019)$ higher in Dll4-overexpressing HUVECs than in the control HUVECs, consistent with previous observations that HEY1/HEY2-deficient mice do not express ephrinB2. ${ }^{52}$ Thus, overexpression of D114 in HUVECs was associated with a significantly enhanced expression of HEY2 and ephrinB2, consistent with enhanced Notch signaling in these cells.

To more directly assess the contribution of Notch signaling to the phenotype of Dll4-transduced HUVECs and distinguish it from the potential contribution of reverse signaling by the intracellular domain of Dll4, we used recombinant human Dll4 (rhDLL4), which lacks the intracellular and transmembrane domains. We found that rhDLL4 immobilized onto culture wells reduced HUVEC proliferation in response to VEGF-A (Figure 6C). In addition, we found that HUVECs cultured on plates coated with rhDLL4 showed decreased surface VEGFR2 expression compared with HUVECs cultured on diluent-coated plates (Figure 6D). These results demonstrate that the extracellular domain of Dll4 is sufficient to inhibit endothelial cell proliferation in response to VEGF-A and to reduce surface VEGFR2 expression. These effects are similar to those induced by full-length Dll4, suggesting that the intracellular and transmembrane domains of Dll4 are not required for activity in the current system, and that Dll4 likely acts through Notch rather than D114 signaling.

Proteolytic processing of Notch by $\gamma$-secretase is an essential step after receptor activation. ${ }^{17}$ As a consequence, $\gamma$-secretase inhibitors block activation of the Notch pathway. To further establish that extracellular D114 inhibits VEGF-A-induced HUVEC proliferation acting through Notch, we used the $\gamma$-secretase inhibitor L-685458. ${ }^{53}$ As shown in Figure 6E, L-685458 specifically and dose dependently reconstituted VEGF-A-induced HUVEC proliferation reduced by rhDLL4. These results are consistent with Dll4 signaling through Notch receptors. 
Figure 6. Expression of Notch receptors in endothelial cells and Notch function in Dll4-transduced cells. (A) mRNAs for Notch receptors 1 to 4 detected by RT-PCR in HUVECs transduced with vector. (B) Quantitative RT-PCR analysis of HEY1, HEY2, ephrinB2, and EphB2 expression in control HUVECs transduced with vector only or DII4overexpressing HUVECs. The results reflect relative mRNA levels (normalized to GAPDH) and are expressed as the mean ( \pm SEM) fold mRNA change in DII4 versus control HUVECs from 2 to 11 separate determinations. ${ }^{*} P<.05$. (C) Effects of immobilized soluble recombinant human DII4 (rhDLL4) on the proliferation of HUVECs. The endothelial cells were cultured for 72 hours in the presence of VEGF-A $(25 \mathrm{ng} / \mathrm{mL})$ on plates coated with rhDLL4 $(1 \mu \mathrm{g} / \mathrm{mL})$ or diluent $(0.1 \% \mathrm{BSA})$; proliferation was measured by ${ }^{3} \mathrm{H}$ thymidine deoxyribose uptake during the last 18 hours of culture. The results reflect the means ( \pm SDs) from triplicate cultures. Representative experiment of 4 performed. ${ }^{\star} P<.05$. (D) Surface levels of VEGFR2 expression in HUVECs cultured for 48 hours onto rhDLL4-coated plates $(1 \mu \mathrm{g} / \mathrm{mL}$ ) (rhDLL4) or diluent-coated plates (gelatin) measured by flow cytometry. Control reflects background surface fluorescence staining with appropriate controls. Representative of 2 performed. (E) Effects of the $\gamma$-secretase inhibitor L-685458 (0.1-7.5 $\mu \mathrm{M})$ on the proliferation of HUVECs cultured with rhDLL4-coated plates $(1 \mu \mathrm{g} / \mathrm{mL})$; proliferation was measured by $\left[{ }^{3} \mathrm{H}\right]$ thymidine deoxyribose uptake during the last 18 hours of culture. The results reflect the means $( \pm S D s$ ) from triplicate cultures. Representative experiment of 4 performed. ${ }^{*} P<.01$ (rhDLL4 with $4 \mu \mathrm{M}$ L-685458 inhibitor versus VEGF alone). ( $F$ ) Quantitative RT-PCR analysis of GAPDH and VEGFR2 expression in vector- and DII4-transduced HUVECs after 72-hour culture with L-685458 $(2 \mu \mathrm{M})$ or diluent only $(0.02 \%$ DMSO). The results reflect relative mRNA levels (normalized to GAPDH) and are expressed as the mean ( \pm SEM) fold mRNA change in DII4-transduced versus control HUVECs from 4 separate experiments, in which levels of VEGFR2 expression in the absence of inhibitor were reduced by at least 5 -fold in DII4-transduced compared with control HUVECs $\left({ }^{\star} P<.05\right)$.

\section{A}

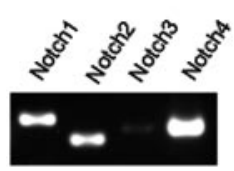

B

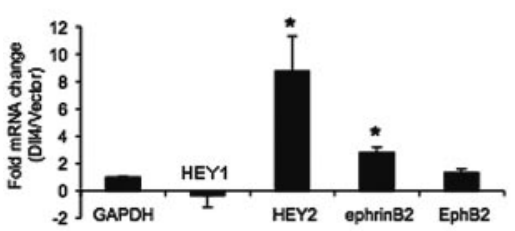

\section{C}

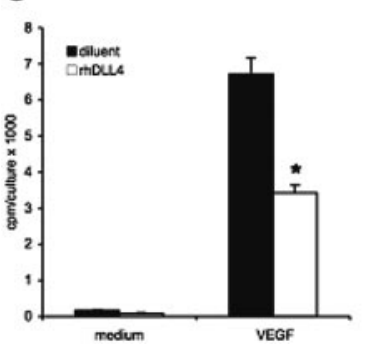

D

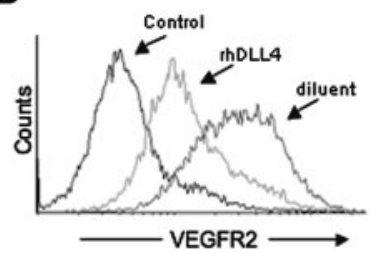

E

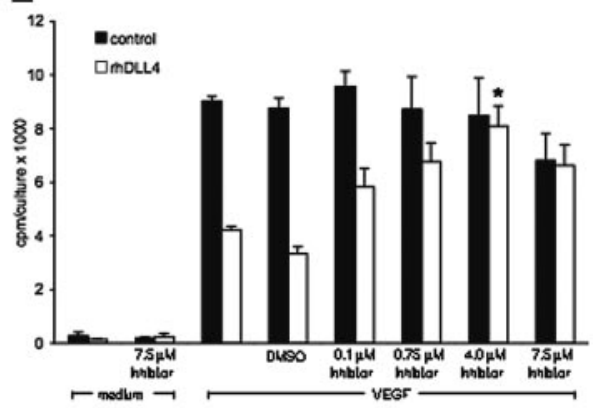

$\mathbf{F}$

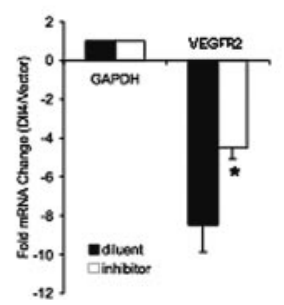

We also tested the effects of the $\gamma$-secretase inhibitor L-685458 on VEGFR2 expression in control and Dll4-overexpressing HUVECs (Figure 6F). When levels of VEGFR2 mRNA were reduced by at least 5 -fold in Dll4-transduced HUVECs compared with vector-transduced HUVECs, L-685458 (2 $\mu \mathrm{M}$, 72-hour incubation) significantly $(P=.041)$ reconstituted VEGFR2 mRNA levels in Dl14-overexpressing HUVECs compared with vectortransduced HUVECs. Reconstitution of VEGFR2 expression was more dependent on defined experimental conditions in Dll4overexpressing HUVECs compared with HUVECs induced by rhDLL4, likely reflecting the complexities of the retroviral expression system. Together, these results provide evidence that Notch signaling contributes to reduced expression of VEGFR2 and reduced proliferation to VEGF-A in Dll4-transduced primary endothelial cells.

\section{Discussion}

In this study, we have expressed Dll4 in primary human endothelial cells by use of retroviral gene transduction and have identified Dll4 as a negative regulator of endothelial cell responses to VEGF-A. We found that Dll4 down-regulates endothelial cell expression of VEGFR2, which is the major mediator of the mitogenic, survival, migration-promoting, and angiogenic activities of VEGF-A. ${ }^{50} \mathrm{We}$ also found that Dll4 down-regulates endothelial cell expression of NRP1, which functions as a coreceptor for members of the VEGF-A family, enhancing VEGFR2 activity. ${ }^{51}$ We and others have shown that Dll4 RNA is induced by hypoxia or VEGF-A in endothelial cells. ${ }^{16,35,41}$ Our current work extends these observa- tions to demonstrate that Dll4 serves to dampen endothelial cell responses to VEGF-A by reducing the expression of its principal signaling receptor and coreceptor.

Previous studies have generally concluded that Notch activation in endothelial cells serves to reduce angiogenic responses. Constitutively active Notch 4 inhibited the sprouting of primary human dermal microvascular endothelial cells and reduced VEGF-induced angiogenesis in the chick chorioallantoic membrane in vivo, in part because of conformational changes in $\beta 1$-integrins. ${ }^{32}$ Overexpression of active Notch1 or Notch4 inhibited the proliferation of HUVECs, in part through repression of $\mathrm{p} 21^{\mathrm{Cip} 1}$ expression. ${ }^{54}$ Constitutively active Notch1 inhibited the migration of mouse embryonic endothelial cells. ${ }^{55}$ In addition, constitutively active Notch1 or Notch4 reduced HUVEC proliferation in response to VEGF but not bFGF. ${ }^{56}$ Consistent with Dll4 being a Notch1 and Notch4 ligand, ${ }^{14,34}$ we have shown that the phenotype of endothelial cells in which Dll4 is overexpressed bears similarity to the phenotype of endothelial cells with active Notch1 or Notch4. Recently, overexpression in HUVECs of Jagged1, another Notch ligand expressed by endothelial cells, induced cell-cycle arrest and reduced cell proliferation, similar to the effect of active Notch1 or Notch4 under the same conditions. ${ }^{54}$ These observations would suggest that in endothelial cells there is at least some functional redundancy not only of Notch1 and Notch4 but also of Jagged1 and Dll4.

Overexpression of D114 in endothelial cells was accompanied by a significant increase in the expression of the transcription factor HEY2 with little or no change in the expression of HEY1. Previously, active Notch1 and Notch4 were shown to up-regulate expression of HEY1 in endothelial cells, ${ }^{56}$ indicating activation of 
different transcription factors by the ligand Dll4 and the active Notch1 or Notch4 receptors. Because Dll4 has been reported to also bind Notch2, ${ }^{15}$ which is expressed on HUVECs and other endothelial cells,${ }^{54}$ it is possible that active Notch 2 may up-regulate HEY2. If Notch receptors can activate different transcription factors depending on the nature of the ligand and perhaps even the degree and precise conditions of activation, this would provide a basis for explanation of the complexities of the Notch system. It is possible that the Dll4 intracellular domain may itself exert specific signaling functions, consistent with what was previously hypothesized for Dll1. ${ }^{57,58}$ However, we have demonstrated that downregulation of VEGFR2 expression and diminished proliferative response to VEGF-A can be achieved through use of the extracellular domain of Dll4 alone. This suggests that the intracellular domain of Dll4 is not necessary for these effects. Furthermore, reduced VEGF-A-induced proliferation caused by extracellular Dll4 can be overcome by the addition of the $\gamma$-secretase inhibitor L-685458, providing strong evidence that Dll4 is signaling through Notch receptors. In addition, an important contribution of Notch signaling to the phenotype of Dll4-overexpressing cells is supported by the results presented here, showing that the inhibitor to Notch signaling L-685458 significantly reconstituted VEGFR2 expression in Dll4-transduced endothelial cells.

We discovered here that overexpression of Dll4 is associated with reduced expression of VEGFR2 and NRP1 in endothelial cells, and this reduction is likely responsible for the abnormally low proliferative and migratory responses to VEGF-A in D114overexpressing endothelial cells. Previously, constitutively active Notch1 and Notch4 in endothelial cells were reported to downregulate VEGFR2 expression probably by decreasing VEGFR2 promoter activity, ${ }^{56}$ and overexpression of HEY1 in these cells reduced levels of VEGFR2 mRNA. ${ }^{49}$ Our results confirm this link between Notch signaling and down-regulation of VEGFR2 and extend this observation in discovering that D1l4 also reduces NRP1 expression. The possibility that NRP1 expression may be regulated by Notch signaling was raised by recent experiments showing that the large arteries, which developed in mice with targeted deletions of Notch1 or HEY1/HEY2, did not express NRP1. ${ }^{52}$

The role of NRP1 as a receptor for class-3 semaphorins, which mediate neuronal guidance, ${ }^{59,60}$ and for several isoforms of VEGF-A, enhancing VEGF-A activity, ${ }^{51}$ is well established. Recently, we and others found that NRP1 regulates endothelial cell adhesion to extracellular matrix and to other cells, ${ }^{43,61}$ indicating that NRP1 is important in angiogenesis both as a modulator of VEGF-A activity and a mediator of endothelial cell adhesion. This conclusion is consistent with the marked vascular abnormalities developing in mice with endothelial cell-targeted deletions of NRP1 ${ }^{62}$ and with embryonic death associated with defects in the heart, vasculature, and nervous system occurring in NRP1-deficient mice. ${ }^{63,64}$ By down-regulating both VEGFR2 and NRP1 expression, Dll4 is positioned to function as an endogenous inhibitor of angiogenesis.

The preferential expression of Dll4 in the developing arteries, arterioles, and capillaries as opposed to veins, ${ }^{14,16}$ the arterialspecific expression of HEY2, ${ }^{65}$ the loss of the CD44 and ephrinB2 arterial endothelial markers in the large arteries of Notch1 or HEY1/HEY2-deficient mice, ${ }^{52}$ and the HEY2-induced expression of many arterial endothelial cell markers in HUVECs ${ }^{65}$ have suggested that the D114-Notch1/4-HEY1/2 pathway specifies arterial endothelial fate during development. ${ }^{30}$ The observation herein that HUVECs overexpressing D114 display increased levels of the arterial marker ephrinB2 mRNA is consistent with this concept. Dll4 expression in the tumor vascular endothelium and angiogenic endothelium of the ovaries and its induction by exposure to hypoxia and VEGF-A ${ }^{16,40,41}$ further suggest that D114 may also play a role in postnatal endothelial cell differentiation processes during angiogenesis.

Our identification of Dll4 as a repressor of endothelial cell responses to VEGF-A, a principal proangiogenic factor, assigns a previously unknown function to D114 and extends current concepts of angiogenesis regulation. The challenge of future experiments will be to evaluate the potential usefulness of D1l4 as an inhibitor of angiogenesis for the treatment of cancer and other disorders characterized by excessive angiogenesis.

\section{Acknowledgments}

We thank Drs R. Schwartz, M. Lenardo, M. Delong, and S. Kennedy for their support; Dr V. Kapoor and W. Telford for cell sorting and flow cytometry support; Dr G. P. Nolan for providing the retroviral vector; Ms L. Sierra, Dr L. Yao, and Dr M. Narazaki for technical support; and Drs N. Patel, S. Suchting, K. Tahtis, and R. Yarchoan for help on various aspects of this work.

C.K.W. is a National Institutes of Health-University of Oxford Health Science Scholar.

\section{References}

1. Greenwald I. LIN-12/Notch signaling: lessons from worms and flies. Genes Dev. 1998;12:17511762.

2. Artavanis-Tsakonas S, Rand MD, Lake RJ. Notch signaling: cell fate control and signal integration in development. Science. 1999;284:770-776.

3. Huppert SS, Le A, Schroeter EH, et al. Embryonic lethality in mice homozygous for a processingdeficient allele of Notch1. Nature. 2000;405:966970.

4. Varnum-Finney B, Xu L, Brashem-Stein C, et al. Pluripotent, cytokine-dependent, hematopoietic stem cells are immortalized by constitutive Notch1 signaling. Nat Med. 2000;6:1278-1281.

5. Calvi LM, Adams GB, Weibrecht KW, et al. Osteoblastic cells regulate the haematopoietic stem cell niche. Nature. 2003;425:841-846.

6. Ellisen LW, Bird J, West DC, et al. TAN-1, the human homolog of the Drosophila notch gene, is broken by chromosomal translocations in T lymphoblastic neoplasms. Cell. 1991;66:649-661.
7. Weinmaster G, Roberts VJ, Lemke G. Notch2: a second mammalian Notch gene. Development. 1992;116:931-941.

8. Lardelli M, Dahlstrand J, Lendahl U. The novel Notch homologue mouse Notch 3 lacks specific epidermal growth factor-repeats and is expressed in proliferating neuroepithelium. Mech Dev. 1994; 46:123-136.

9. Uyttendaele H, Marazzi G, Wu G, Yan Q, Sassoon D, Kitajewski J. Notch4/int-3, a mammary proto-oncogene, is an endothelial cell-specific mammalian Notch gene. Development. 1996; 122:2251-2259.

10. Lindsell CE, Shawber CJ, Boulter J, Weinmaster G. Jagged: a mammalian ligand that activates Notch1. Cell. 1995;80:909-917.

11. Shawber C, Nofziger D, Hsieh JJ, et al. Notch signaling inhibits muscle cell differentiation through a CBF1-independent pathway. Development. 1996;122:3765-3773.

12. Bettenhausen B, Gossler A. Efficient isolation of novel mouse genes differentially expressed in early postimplantation embryos. Genomics. 1995; 28:436-441.

13. Dunwoodie SL, Henrique D, Harrison SM, Beddington RS. Mouse DII3: a novel divergent Delta gene which may complement the function of other Delta homologues during early pattern formation in the mouse embryo. Development. 1997;124:3065-3076.

14. Shutter JR, Scully S, Fan W, et al. DIl4, a novel Notch ligand expressed in arterial endothelium. Genes Dev. 2000;14:1313-1318.

15. Rao PK, Dorsch M, Chickering $T$, et al. Isolation and characterization of the notch ligand delta4. Exp Cell Res. 2000;260:379-386.

16. Mailhos C, Modlich U, Lewis J, Harris A, Bicknell $\mathrm{R}$, Ish-Horowicz D. Delta4, an endothelial specific notch ligand expressed at sites of physiological and tumor angiogenesis. Differentiation. 2001;69: 135-144.

17. Mumm JS, Kopan R. Notch signaling: from the outside in. Dev Biol. 2000;228:151-165. 
18. Bailey AM, Posakony JW. Suppressor of hairless directly activates transcription of enhancer of split complex genes in response to Notch receptor activity. Genes Dev. 1995;9:2609-2622.

19. Jarriault S, Brou C, Logeat F, Schroeter EH, Kopan R, Israel A. Signalling downstream of activated mammalian Notch. Nature. 1995;377:355358.

20. Leimeister C, Schumacher N, Steidl C, Gessler $M$. Analysis of HeyL expression in wild-type and Notch pathway mutant mouse embryos. Mech Dev. 2000;98:175-178.

21. Kokubo H, Lun $Y$, Johnson RL. Identification and expression of a novel family of bHLH cDNAs related to Drosophila hairy and enhancer of split. Biochem Biophys Res Commun. 1999;260:459465.

22. Iso T, Sartorelli V, Poizat C, et al. HERP, a novel heterodimer partner of $\mathrm{HES} / \mathrm{E}(\mathrm{spl})$ in Notch signaling. Mol Cell Biol. 2001;21:6080-6089.

23. Iso T, Sartorelli V, Chung G, Shichinohe T, Kedes L, Hamamori Y. HERP, a new primary target of Notch regulated by ligand binding. Mol Cell Biol. 2001;21:6071-6079.

24. Lawson ND, Weinstein BM. Arteries and veins: making a difference with zebrafish. Nat Rev Genet. 2002;3:674-682.

25. Rossant J, Howard L. Signaling pathways in vascular development. Annu Rev Cell Dev Biol. 2002;18:541-573

26. Shawber CJ, Kitajewski J. Notch function in the vasculature: insights from zebrafish, mouse and man. Bioessays. 2004;26:225-234.

27. Shirayoshi Y, Yuasa Y, Suzuki T, et al. Protooncogene of int-3, a mouse Notch homologue, is expressed in endothelial cells during early embryogenesis. Genes Cells. 1997;2:213-224.

28. Del Amo FF, Smith DE, Swiatek PJ, et al. Expression pattern of Motch, a mouse homolog of Drosophila Notch, suggests an important role in early postimplantation mouse development. Development. 1992;115:737-744.

29. Reaume AG, Conlon RA, Zirngibl R, Yamaguchi TP, Rossant J. Expression analysis of a Notch homologue in the mouse embryo. Dev Biol. 1992; 154:377-387.

30. Krebs LT, Xue Y, Norton CR, et al. Notch signaling is essential for vascular morphogenesis in mice. Genes Dev. 2000;14:1343-1352.

31. Uyttendaele H, Ho J, Rossant J, Kitajewski J. Vascular patterning defects associated with expression of activated Notch4 in embryonic endothelium. Proc Natl Acad Sci U S A. 2001;98:56435648.

32. Leong KG, Hu X, Li L, et al. Activated Notch4 inhibits angiogenesis: role of beta 1-integrin activation. Mol Cell Biol. 2002;22:2830-2841.

33. Yoneya T, Tahara T, Nagao K, et al. Molecular cloning of delta-4, a new mouse and human Notch ligand. J Biochem (Tokyo). 2001;129:2734.

34. Shawber CJ, Das I, Francisco E, Kitajewski J. Notch signaling in primary endothelial cells. Ann N Y Acad Sci. 2003;995:162-170.
35. Gale NW, Dominguez MG, Noguera I, et al. Haploinsufficiency of delta-like 4 ligand results in embryonic lethality due to major defects in arteria and vascular development. Proc Natl Acad Sci U S A. 2004;101:15949-15954.

36. Krebs LT, Shutter JR, Tanigaki K, Honjo T, Stark $\mathrm{KL}$, Gridley T. Haploinsufficient lethality and formation of arteriovenous malformations in Notch pathway mutants. Genes Dev. 2004;18:2469 2473.

37. Duarte A, Hirashima M, Benedito R, et al. Dosage-sensitive requirement for mouse DII4 in artery development. Genes Dev. 2004;18:24742478.

38. Carmeliet P, Ferreira V, Breier G, et al. Abnormal blood vessel development and lethality in embryos lacking a single VEGF allele. Nature. 1996; 380:435-439.

39. Ferrara N, Carver-Moore K, Chen $\mathrm{H}$, et al. Heterozygous embryonic lethality induced by targeted inactivation of the VEGF gene. Nature. 1996;380:439-442.

40. Shweiki D, Itin A, Soffer D, Keshet E. Vascular endothelial growth factor induced by hypoxia may mediate hypoxia-initiated angiogenesis. Nature. 1992;359:843-845.

41. Liu ZJ, Shirakawa T, Li Y, et al. Regulation of Notch 1 and DII4 by vascular endothelial growth factor in arterial endothelial cells: implications for modulating arteriogenesis and angiogenesis. Mol Cell Biol. 2003;23:14-25.

42. Murga M, Yao L, Tosato G. Derivation of endothelial cells from CD34- umbilical cord blood. Stem Cells. 2004;22:385-395.

43. Murga M, Fernandez-Capetillo O, Tosato G. Neuropilin-1 regulates attachment in human endothelial cells independently of vascular endothelial growth factor receptor-2. Blood. 2005;105:19921999.

44. Cherney BW, Bhatia K, Tosato G. A role for deregulated c-Myc expression in apoptosis of $\mathrm{Ep}$ stein-Barr virus-immortalized B cells. Proc Natl Acad Sci U S A. 1994;91:12967-12971.

45. Salvucci O, Yao L, Villalba S, Sajewicz A, Pittaluga S, Tosato G. Regulation of endothelial cell branching morphogenesis by endogenous chemokine stromal-derived factor-1. Blood. 2002;99: 2703-2711.

46. Kubota Y, Kleinman HK, Martin GR, Lawley TJ. Role of laminin and basement membrane in the morphological differentiation of human endothelial cells into capillary-like structures. J Cell Biol. 1988; 107:1589-1598.

47. Saito M, Hamasaki M, Shibuya M. Induction of tube formation by angiopoietin-1 in endothelial cell/fibroblast co-culture is dependent on endogenous VEGF. Cancer Sci. 2003;94:782-790.

48. Conway EM, Collen D, Carmeliet P. Molecular mechanisms of blood vessel growth. Cardiovasc Res. 2001;49:507-521.

49. Henderson AM, Wang SJ, Taylor AC, Aitkenhead $M$, Hughes CC. The basic helix-loop-helix transcription factor HESR1 regulates endothelial cell tube formation. J Biol Chem. 2001;276:61696176.
50. Ferrara N, Gerber HP, LeCouter J. The biology of VEGF and its receptors. Nat Med. 2003;9:669676.

51. Soker S, Takashima S, Miao HQ, Neufeld G, Klagsbrun M. Neuropilin-1 is expressed by endo thelial and tumor cells as an isoform-specific receptor for vascular endothelial growth factor. Cell. 1998;92:735-745.

52. Fischer A, Schumacher N, Maier M, Sendtner M, Gessler M. The Notch target genes Hey1 and Hey2 are required for embryonic vascular development. Genes Dev. 2004;18:901-911.

53. Li YM, Xu M, Lai MT, et al. Photoactivated gammasecretase inhibitors directed to the active site covalently label presenilin 1. Nature. 2000;405:689694.

54. Noseda M, Chang L, McLean G, et al. Notch activation induces endothelial cell cycle arrest and participates in contact inhibition: role of p21Cip1 repression. Mol Cell Biol. 2004;24:8813-8822.

55. Itoh F, Itoh S, Goumans MJ, et al. Synergy and antagonism between Notch and BMP receptor signaling pathways in endothelial cells. EMBO J. 2004;23:541-551.

56. Taylor KL, Henderson AM, Hughes CC. Notch activation during endothelial cell network formation in vitro targets the basic $\mathrm{HLH}$ transcription factor HESR-1 and downregulates VEGFR-2/ KDR expression. Microvasc Res. 2002;64:372383.

57. Wright GJ, Leslie JD, Ariza-McNaughton L, Lewis J. Delta proteins and MAGI proteins: an interaction of Notch ligands with intracellular scaffolding molecules and its significance for zebrafish development. Development. 2004;131:5659-5669.

58. Pfister S, Przemeck GK, Gerber JK, Beckers J, Adamski J, Hrabe de Angelis M. Interaction of the MAGUK family member Acvrinp1 and the cytoplasmic domain of the Notch ligand Delta1. J Mol Biol. 2003;333:229-235.

59. He Z, Tessier-Lavigne M. Neuropilin is a receptor for the axonal chemorepellent Semaphorin III. Cell. 1997;90:739-751.

60. Kolodkin AL, Levengood DV, Rowe EG, Tai YT, Giger RJ, Ginty DD. Neuropilin is a semaphorin III receptor. Cell. 1997;90:753-762.

61. Shimizu M, Murakami Y, Suto F, Fujisawa H. Determination of cell adhesion sites of neuropilin-1. J Cell Biol. 2000;148:1283-1293.

62. Gu C, Rodriguez ER, Reimert DV, et al. Neuropilin-1 conveys semaphorin and VEGF signaling during neural and cardiovascular development. Dev Cell. 2003;5:45-57.

63. Kitsukawa T, Shimizu M, Sanbo M, et al. Neuropilin-semaphorin III/D-mediated chemorepulsive signals play a crucial role in peripheral nerve projection in mice. Neuron. 1997;19:995-1005.

64. Kawasaki T, Kitsukawa T, Bekku Y, et al. A requirement for neuropilin-1 in embryonic vessel formation. Development. 1999;126:4895-4902.

65. Chi JT, Chang HY, Haraldsen G, et al. Endothelial cell diversity revealed by global expression profiling. Proc Natl Acad Sci U S A. 2003;100:1062310628. 


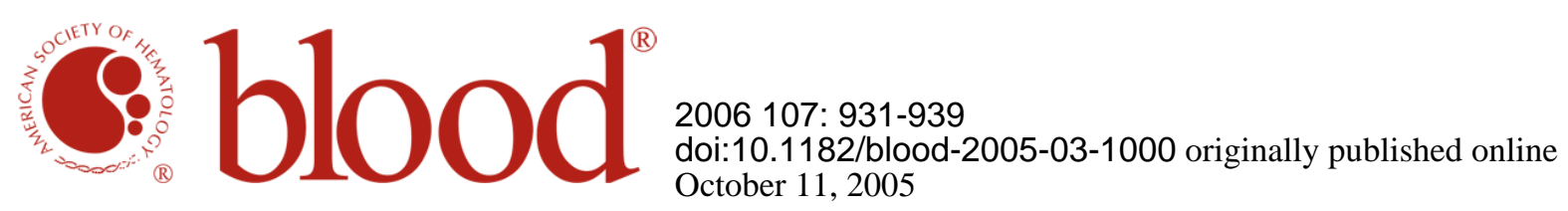

\section{Up-regulation of the Notch ligand Delta-like 4 inhibits VEGF-induced endothelial cell function}

Cassin Kimmel Williams, Ji-Liang Li, Matilde Murga, Adrian L. Harris and Giovanna Tosato

Updated information and services can be found at: http://www.bloodjournal.org/content/107/3/931.full.html

Articles on similar topics can be found in the following Blood collections Hemostasis, Thrombosis, and Vascular Biology (2485 articles)

Signal Transduction (1930 articles)

Information about reproducing this article in parts or in its entirety may be found online at: http://www.bloodjournal.org/site/misc/rights.xhtml\#repub_requests

Information about ordering reprints may be found online at:

http://www.bloodjournal.org/site/misc/rights.xhtml\#reprints

Information about subscriptions and ASH membership may be found online at: http://www.bloodjournal.org/site/subscriptions/index.xhtml 